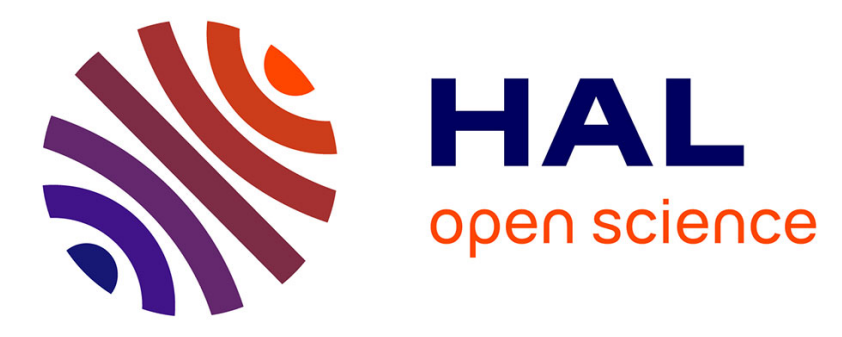

\title{
Neutrophil extracellular traps are associated with the pathogenesis of diffuse alveolar hemorrhage in murine lupus
}

\author{
Pierre-André Jarrot, Edwige Tellier, Léa Plantureux, Lydie Crescence, \\ Stéphane Robert, Corinne Chareyre, Laurent Daniel, Véronique Secq, \\ Stephane Garcia, Francoise Dignat-George, et al.
}

\section{To cite this version:}

Pierre-André Jarrot, Edwige Tellier, Léa Plantureux, Lydie Crescence, Stéphane Robert, et al.. Neutrophil extracellular traps are associated with the pathogenesis of diffuse alveolar hemorrhage in murine lupus. Journal of Autoimmunity, 2019, 100, pp.120-130. 10.1016/j.jaut.2019.03.009 . hal-02542311

\section{HAL Id: hal-02542311 \\ https: / hal-amu.archives-ouvertes.fr/hal-02542311}

Submitted on 22 Oct 2021

HAL is a multi-disciplinary open access archive for the deposit and dissemination of scientific research documents, whether they are published or not. The documents may come from teaching and research institutions in France or abroad, or from public or private research centers.
L'archive ouverte pluridisciplinaire HAL, est destinée au dépôt et à la diffusion de documents scientifiques de niveau recherche, publiés ou non, émanant des établissements d'enseignement et de recherche français ou étrangers, des laboratoires publics ou privés.

\section{(ㄷ)(1) $\$$}

Distributed under a Creative Commons Attribution - NonCommerciall 4.0 International 


\title{
Neutrophil extracellular traps are associated with the pathogenesis of diffuse alveolar hemorrhage in murine lupus
}

\author{
Pierre-André Jarrot ${ }^{\mathrm{a}, \mathrm{b}}$, Edwige Tellier ${ }^{\mathrm{a}}$, Lea Plantureux ${ }^{\mathrm{a}}$, Lydie Crescence ${ }^{\mathrm{a}}$, \\ Stéphane Robert ${ }^{\text {a }}$, Corinne Chareyre ${ }^{\text {a }}$, Laurent Daniel ${ }^{\mathrm{c}}$, Véronique Secq ${ }^{\mathrm{d}}$, \\ Stéphane Garcia ${ }^{\mathrm{d}}$, Françoise Dignat-George ${ }^{\mathrm{a}, \mathrm{e}}$, Laurence Panicot-Dubois ${ }^{\mathrm{a}}$, \\ Christophe Dubois ${ }^{\text {a }}$, Gilles Kaplanski ${ }^{\text {a,b }}$
}

${ }^{\text {a }}$ Centre for Cardiovascular and Nutrition Research (C2VN), INRA 1260, INSERM UMR_S 1263, Aix-Marseille University, Marseille, France

${ }^{\mathrm{b}}$ Department of Internal Medicine and Clinical Immunology CHU Conception, Assistance Publique-Hôpitaux de Marseille (AP-HM), Marseille, France

${ }^{\mathrm{c}}$ Laboratory of Pathology, CHU La Timone, AP-HM, Marseille, France

${ }^{\mathrm{d}}$ Laboratory of Pathology, CHU Nord, AP-HM, Marseille, France

${ }^{\mathrm{e}}$ Laboratory of Haematology, CHU La Conception, AP-HM, Marseille, France

\section{Corresponding author:}

Dr Pierre-André Jarrot / Pr Gilles Kaplanski, Department of Internal Medicine and Clinical Immunology, CHU Conception, 148 boulevard Baille, 13005 Marseille, France.

Phone: (+33) 4913835 22; Fax: (+33) 4913824 99; E-mail: pierre.jarrot@ap-hm.fr 


\begin{abstract}
Diffuse alveolar hemorrhage (DAH) is a life-threatening complication of systemic lupus erythematosus (SLE) and systemic vasculitis. Although initially described to have antibacterial properties, increasing evidence suggests that neutrophil extracellular traps (NETs) have a detrimental role in both autoimmune diseases and acute lung injury. We investigated whether NETs could be detected in a murine model of pristane-induced lupus DAH and contribute to lung injury. Such NETs might constitute a therapeutic target. NETs were characterized by immunofluorescence staining of DNA, neutrophil elastase and citrullinated histones. Evaluation of lung injury was performed by haematoxylin-eosin staining and a quantification program. Clinical status of the mice was assessed by measurement of arterial oxygen saturation and survival curves after recombinant human deoxyribonuclease-1 (Rh-DNase-1) inhalations or polymorphonuclear neutrophil (PMN) depletion. Pristane was found to promote NETs formation in vitro and in vivo. Treatment of mice with Rh-DNase-1 inhalations cleared NETs and reduced lung injury. Clinical status improved significantly, with increased arterial oxygenation and survival. Following PMN depletion, NETs were absent with a subsequent reduction of lung injury and improved arterial oxygenation. These results support a pathogenic role of PMNs and NETs in lung injury during pristane-induced DAH. Targeting NETs with Rh-DNase-1 inhalations could constitute an interesting adjuvant therapy in human DAH.
\end{abstract}

Keywords: Neutrophil extracellular traps; Deoxyribonuclease-1; Diffuse alveolar hemorrhage; Murine model; Systemic lupus erythematosus 


\section{Highlights}

- Pristane-induced diffuse alveolar hemorrhage lupus model can be considered as a pulmonary model of NETosis.

- Targeting the NETs scaffold with recombinant human deoxyribonuclease-1 reduced severity of diffuse alveolar hemorrhage lesions and improves animal clinical status.

- Recombinant human deoxyribonuclease-1 may could be an interesting adjuvant therapy in human diffuse alveolar hemorrhage. 


\section{Introduction}

Diffuse alveolar hemorrhage (DAH) is defined by the presence of red blood cells originating from the lung capillaries or veins in the alveoli, often leading to acute respiratory failure, and constitutes a therapeutic emergency [1]. The prognosis is poor with a $20 \%$ mortality rate due to limited therapeutic options [2,3]. The diagnosis is based on clinical features (haemoptysis, dyspnoea), anaemia, radiological patterns and, most importantly, examination of bronchoalveolar lavage. Although there are many underlying causes, autoimmune diseases such as systemic lupus erythematosus (SLE), antineutrophil-cytoplasmic antibody (Ab) (ANCA)-associated vasculitis and antiglomerular basement membrane Ab disease account for $35 \%$ of all causes and constitute the main aetiologies [4]. Histopathologically, in addition to the presence of haemosiderin-laden macrophages and bland hemorrhage, interstitial infiltrates consisting of polymorphonuclear neutrophils (PMNs), which constitute pulmonary capillaritis and subsequent necrotizing vasculitis, are commonly observed [5].

Activated PMNs have been described to produce neutrophil extracellular traps (NETs), primarily through a cell-death process distinct from apoptosis and necrosis, termed NETosis. NETs are composed of chromatin filaments coated with histones, proteases, granular and cytosolic proteins [6]. Although NETs were previously described for their antibacterial properties due to the trapping and killing of extracellular pathogens in blood and tissue during infection, they have also been reported to play a detrimental role in acute lung injury, SLE and ANCA-associated vasculitis [7, 8]. NETs have been detected in the lungs during transfusion-related acute lung injury, an immune process related to DAH and shown to play a direct role in lung injury. In addition, treatment with deoxyribonuclease-1 (DNase-1), known to disrupt the NETs scaffold, has been shown to be beneficial in a murine model of transfusion-related acute lung injury $[9,10]$. 
In the first 15 days after intraperitoneal (IP) injection, C57BL/6 mice with pristane-induced SLE develop massive DAH, which is characterized by capillaritis, hemorrhage and endothelial injury $[11,12]$. Previous studies have shown that pristane can induce the recruitment of PMNs into the peritoneal cavity with the subsequent development of chronic peritonitis [13-15]. Although PMN recruitment has also been reported in the lungs of animals with pristane-induced DAH, their role in the pathogenesis of DAH is unclear.

The present study was carried out to determine whether NETs were formed in the lungs of mice with pristane-induced DAH and contributed to lung injury. Such NETs could be a potential therapeutic target using recombinant human DNase-1 (Rh-DNase-1), also known as dornase alpha (Pulmozyme $\left.{ }^{\circledR}\right)$, a well-known mucolytic drug commonly used in patients with cystic fibrosis [16].

\section{Material and methods}

\subsection{Mice}

Wild-type C57BL/6 JRj (B6) mice were purchased from Elevage Janvier (Le Genest-SaintIsle, France). All experimental procedures were performed in 8- to 12-week-old male mice housed under specific pathogen-free conditions in the laboratory animal facility. All animal care and experimental procedures were performed according to European Community Guidelines (directive 2010/63/UE) and approved by the Marseille Ethics Committee \#14 (protocol number: 2015113014168292-V4 \#2934).

\subsection{Isolation of mouse PMNs}

PMNs were isolated from the bone marrow of B6 mice as described previously using PE (phycoerythrin)-coupled magnetic microbeads and PE anti-Ly6G Ab (3 $\mu \mathrm{g} / \mathrm{mL}$; Miltenyi Biotec, Paris, France) [17]. Briefly, the bone marrow was flushed out of the tibia and femur 
using phosphate-buffered calcium-free saline (PBS-/-) (Thermofischer, Villebon sur Yvette, France) supplemented with $0.5 \%$ bovine serum albumin (BSA) and EDTA (2 mM) (SigmaAldrich, Saint-Quentin-Fallavier, France), passed through a $70-\mu \mathrm{m}$ cell trainer to obtain a single cell solution and centrifuged at $300 \mathrm{~g}$ for $8 \mathrm{~min}$. The pellet was resuspended in PBS-/-, $0.5 \% \mathrm{BSA}$ and $2 \mathrm{mM}$ EDTA, stained with PE anti-Ly6G Ab for $10 \mathrm{~min}$ in the dark at $4{ }^{\circ} \mathrm{C}$ and completed with anti-PE microbeads for $15 \mathrm{~min}$ in the dark at $4{ }^{\circ} \mathrm{C}$. Positive immune-magnetic separation of PMNs was performed using LS columns (Miltenyi Biotec, Paris, France). Cells were then washed and resuspended in Hanks balanced salt solution containing calcium (HKS+/+) (Thermofischer, Villebon sur Yvette, France). PMN count was determined using Kova slides (Jeulin, Evreux, France) and viability (>90\%) was assessed using the trypan blue (Sigma-Aldrich, Saint-Quentin-Fallavier, France) exclusion method. PMN purity was routinely $>98 \%$, as assessed by flow cytometry using PE anti-Ly6G Ab staining.

\subsection{In vitro NETs experiments}

After isolation, PMNs $\left(5 \times 10^{5}\right)$ were allowed to adhere to poly-L-lysine (Sigma-Aldrich, Saint-Quentin Fallavier, France) coated slides in a $24-$ well plate at $37^{\circ} \mathrm{C}$ and $5 \% \mathrm{CO}_{2}$ for 30 min. The attached PMNs were incubated with various stimuli at $37^{\circ} \mathrm{C}, 5 \% \mathrm{CO}_{2}$ for $180 \mathrm{~min}$. Some experiments were performed with the addition of Rh-DNase-1 (dornase alpha; Pulmozyme $^{\circledR}, 2500 \mathrm{U} / 2.5 \mathrm{~mL}(1 \mathrm{mg} / \mathrm{mL})$, purity >97\%; Roche, ATC: R05C B13, BoulogneBillancourt, France), at a concentration of $2 \mu \mathrm{g} / \mathrm{ml}$ for $10 \mathrm{~min}$ (at the end of stimulation). Platelet activating factor (PAF; Calbiochem, Molsheim, France) at a concentration of $10 \mu \mathrm{M}$ was used as a positive control for NETs formation [18]. Pristane was either applied directly (2 min) or as a complex with $\beta$-cyclodextrin $(\beta-C D)$ (Sigma-Aldrich, Saint-Quentin Fallavier, France). All experiments were performed in $\mathrm{HKS}+/+$ (without any media supplements). For formation of complexes, a $4 \mathrm{mM}$ solution of $\beta$-CD was mixed with pristane $(2 \mathrm{mM}$ final 
concentration) and stirred for 4 days at room temperature, as described previously [19]. All complexes were prediluted at $1 / 150$ in $\mathrm{HKS}+/+$, which was considered as concentration 1 $(\mathrm{C} 1=13.3 \mu \mathrm{M})$. After stimulation, the cells were fixed with $4 \%$ paraformaldehyde (SigmaAldrich, Saint-Quentin Fallavier, France) before washing 3 times with PBS-/- and blocked with 3\% BSA for immunofluorescence (IF) staining. Cells were then incubated overnight at $4^{\circ} \mathrm{C}$ in the dark with an anti-murine histone 3 rabbit polyclonal $\mathrm{Ab}$ (citrulline residues $\mathrm{R} 2, \mathrm{R} 8$, R17) (H3Cit) (ab5103, $10 \mu \mathrm{g} / \mathrm{mL}$ ) or with an anti-murine neutrophil elastase (NE) rabbit polyclonal Ab (ab21595, $25 \mu \mathrm{g} / \mathrm{mL})$, both purchased from Abcam (Paris, France). After washing three times with PBS-/-, a secondary rabbit-specific polyclonal Ab conjugated with 488-Alexa Fluor Dyes (Invitrogen, Villebon sur Yvette, France) was added to cells and incubated in the dark for $1 \mathrm{~h}$ at $37^{\circ} \mathrm{C}$. Specificity of primary Ab staining was determined with a control rabbit irrelevant Ab (Sigma-Aldrich, R9133, lot SLB7964V, Saint-Quentin Fallavier, France). DNA was stained using Hoechst 33342 (Molecular Probes, Villebon sur Yvette, France) and the cells were mounted in fluoromount $-G^{\mathrm{TM}}$ medium (eBioscience SAS, Paris, France) for imaging with a Leica Microsystem DMi8 microscope (Nanterre, France). The image files were analysed with Image J 1.49v software (National Institutes of Health, USA).

In vitro NETs formation was quantified using a modified method reported previously [20]. Briefly, using the $\mathrm{x} 10$ objective, the percentage of PMNs releasing NETs was quantified in blinded samples by evaluating PMNs releasing DNA fibres with NE or H3Cit co-staining. NETs percentage was calculated as follows: NETs-rate $(\%)=100 \mathrm{x}$ number of PMNs releasing DNA fibres with NE or H3Cit co-staining/total number of PMNs. Quantification was performed using two delimited standardised plots using at least five random microscopic fields per condition. 


\subsection{Pristane-induced DAH model}

Mice received a single IP injection of $0.5 \mathrm{ml}$ synthetic sterile-filtered liquid pristane (SigmaAldrich, Saint-Quentin Fallavier, France). In order to avoid any non-specific stimulation of peritoneal cells by calcium, control mice received a $0.5 \mathrm{~mL}$ PBS-/- IP injection [21]. Mice were weighed every day. Their lungs and blood were harvested on day 14 for pathological investigations except for mice included in the survival assay.

\subsection{Recombinant human DNase-1 inhalation therapy}

All mice received the same protocol of Rh-DNase-1 (Pulmozyme ${ }^{\circledR}$ ) inhalations $(0.8$ $\mathrm{mg} /$ inhalation, once a day until day 9, then three times a day from day 10) in a special inhalation chamber (size 7.5” L x 5.5" W x 4" H, 39481051; Leica, Nanterre, France) using a Stratos Pro inhaler (Invacare, Fondettes, France). Control mice received $0.9 \% \mathrm{NaCl}$ inhalations, following the same protocol as for Rh-DNase-1 therapy.

\subsection{In vivo $\mathrm{PMN}$ depletion}

PMNs were depleted in vivo by treating mice with Ultra-LEAF ${ }^{\mathrm{TM}}$ purified anti-mouse Ly6G Ab clone 1A8 (Biolegend, Saint Quentin en Yvelines, France) using one IP injection (170 $\mu \mathrm{g} /$ mouse) the day before and every other day after IP pristane injection, until day $14[22,23]$. PMN depletion was assessed by flow cytometry after staining with anti-CD45 efluor780, antiCD11b-APC (ebioscience ${ }^{\mathrm{TM}}$, Villebon sur Yvette, France) and anti-PE-Ly6G (Miltenyi Biotec, Paris, France). 


\subsection{Pathological investigations}

Mice were euthanized on day 14 and their lung tissue was harvested immediately after death. The left lobes were fixed overnight in $10 \%$ buffered formalin (Sigma-Aldrich, Saint-Quentin Fallavier, France) and embedded in paraffin. The right lobes were frozen with optimal cutting temperature (OCT) compound (Sigma-Aldrich, Saint-Quentin Fallavier, France). Paraffinembedded sections were cut into $5 \mu \mathrm{m}$ sections and stained with haematoxylin-eosin (H\&E) (Sigma-Aldrich, Saint-Quentin Fallavier, France). The extent of pulmonary hemorrhage was assessed using quantification program CaloPix ${ }^{\circledR}$ software (TRIBVN Healthcare, Chatillon, France), which is a digital slide and management software. Two blinded pathologists assessed the extent of DAH. Total, white (no tissue) and healthy areas were defined numerically at x20 magnification. Two standardised slides of each left lung were analysed. The extent of DAH was calculated as follows: DAH $(\%)=100-($ healthy area / (total - white area) x 100 .

OCT-embedded frozen lung lobes were cut into $5 \mu \mathrm{m}$ sections and fixed with acetone (10 min). After washing three times with PBS-/-, slides were blocked with 3\% BSA. Sections were then incubated with $0.3 \mu \mathrm{g} / \mathrm{mL}$ PE-anti-Ly6G Ab (Miltenyi Biotec, Paris, France), antiH3Cit $(30 \mu \mathrm{g} / \mathrm{mL})$ or anti-NE rabbit $(50 \mu \mathrm{g} / \mathrm{mL})$ polyclonal Ab overnight at $4^{\circ} \mathrm{C}$. Sections were then washed and incubated with secondary rabbit-specific polyclonal Ab conjugated with 649-Alexa Fluor Dyes (Invitrogen, Villebon sur Yvette, France) (dark, 1 h, $37^{\circ} \mathrm{C}$ ). DNA was stained using Hoechst 33342 (Molecular Probes, Villebon sur Yvette, France). Sections were mounted in fluoromount- $\mathrm{G}^{\mathrm{TM}}$ medium (eBioscience SAS, Paris, France) for imaging microscopy.

Quantification of NE and H3Cit fluorescence was performed at x10 magnification in one random microscopic field of each lobe per mouse, followed by binary analysis using Image $\mathrm{J}$ 
$1.49 \mathrm{v}$ software $(\mathrm{NIH}, 2015)$. PMN count was assessed in the same microscopic field as NE and $\mathrm{H} 3 \mathrm{Cit}$ staining.

\subsection{Confocal laser scanning microscopy}

The same histological samples were analysed using a Zeiss ${ }^{\circledR}$ LSM 800 confocal microscope with Airyscan technology using a x63 oil immersion objective.

\subsection{Pulse-oximetry assay}

Real-time $\mathrm{SpO}_{2}$ (percentage of functional arterial haemoglobin) was measured using a MouseOx pulse-oximeter (Starr Life Sciences, Oakmont, USA).

\subsection{Statistical analysis}

Data are representative of at least three independent experiments. Results are reported as both individual data points, mean \pm standard deviation $(\mathrm{SD})$. To determine statistical significance, the 2-tailed unpaired Student's $t$ test was used for normally distributed data. Survival rates were compared using the log-rank (Mantel-Cox) test.

GraphPad Prism 5.0 software was used for all statistical analyses. $P$ values $<0.05$ were considered statistically significant.

\section{Results}

\subsection{Pristane promotes NETs formation in vitro}

PMNs are considered to be key players in the initiation of inflammation involved in the development of haemorrhage-induced acute lung injury. Because a single IP injection of pristane is known to induce rapid PMN recruitment in the lungs, preceding DAH by a few days $[24,25]$, we tested whether this hydrocarbon oil could promote NETs formation in vitro. 
Because of its extreme hydrophobicity, pristane was applied to murine PMNs, either directly or complexed with $\beta$-CD. $\beta$-CD is an oligomer of D-glucose with a hydrophobic cavity and a hydrophilic surface and complexes of pristane and $\beta$-CD have been shown to be effective at delivering pristane in vitro [19]. The dose of pristane chosen in our experiments was adjusted in accordance with a previous study [14]. PAF-treated PMNs were used as a positive control for NETs formation. Different concentrations of $\beta$-CD-complexed pristane were tested $(\mathrm{C} 1=13.3 \mu \mathrm{M}, \mathrm{C} 1 / 10, \mathrm{C} 2(\mathrm{C} 1 \mathrm{x} 2))$ and compared with the effect of PAF. NET formation was determined by the colocalization of DNA fibres, extracellular H3Cit proteins or NE [26].

Using fluorescence microscopy, a significant increase in NETs formation was observed after incubation of PMNs with $\beta$-CD-complexed or directly applied pristane, in comparison with PMNs incubated with a control solution (Fig. 1A-D; $P<0.001$ ).

\subsection{Pristane causes NETs formation in the lungs in vivo}

We used a previously established in vivo model of pristane-induced DAH, whose hemorrhage started 3 days after pristane injection, peaked at 2 weeks and then resolved by 4 weeks in $70 \%$ of mice [25]. At day 15, the airspaces of the lungs of pristane-treated mice were filled with fresh haemorrhage and were heavily infiltrated with macrophages and PMNs compared with untreated animals (Supplemental Fig. 1A-B). The release of NE, H3Cit and number of PMNs (characterized by colocalization of Ly6G and DNA staining) were quantified in the lungs. Significantly stronger NE and H3Cit staining and a higher number of PMNs were detected in the lungs of mice with pristane-induced DAH compared with the lungs of healthy controls (HC) (Fig. 2A-D, $P<0.001$ ). In addition, using confocal fluorescence microscopy, we observed diffuse DNA structures of irregular shape, which colocalized with Ly6G (corresponding to PMN membranes) and with NE or H3Cit staining, in favour of NETs (Fig. $2 \mathrm{E}, \mathrm{F})$. In agreement with these observations, in vivo depletion of PMNs using anti-Ly6G 
clone $1 \mathrm{~A} 8$ monoclonal $\mathrm{Ab}$ prevented the appearance of PMNs, NE and $\mathrm{H} 3 \mathrm{Cit}$ formation in the lungs of mice with pristane-induced DAH (Fig. 3A-D, $P<0.001$ ).

Taken together, these results suggest that a single IP injection of pristane caused NETs formation in the lungs of B6 mice.

\subsection{Recombinant human DNase-1 disrupts NETs formation and attenuates lung injury in a pristane-induced DAH murine model}

In order to determine whether NETs could serve as a therapeutic target in pristane-induced DAH we used Rh-DNase-1, which is known to catalyse the hydrolysis of the NETs backbone structure. It was confirmed in vitro that pristane-induced NETs could be dismantled by RhDNase-1 (Supplemental Fig. 2, $P<0.001$ ). We then treated mice with inhalations of RhDNase-1, starting the day after IP pristane injection. Rh-DNase-1 treatment significantly reduced $\mathrm{NE}$ and $\mathrm{H} 3 \mathrm{Cit}$ fluorescence staining in the lungs of mice with pristane-induced DAH compared with the lungs of untreated mice, and appeared comparable to the lungs of $\mathrm{HC}$ mice. Furthermore, a decrease in the PMN count in the lungs was observed after Rh-DNase-1 therapy (Fig. 4A-E, $P<0.001$ ).

In order to determine whether Rh-DNase-1 inhalation reduced acute hemorrhagic injury lesions, we quantified DAH lesions after H\&E staining of lung sections. Rh-DNase-1 therapy significantly reduced DAH lesions compared with untreated animals (Fig. 5A-D, $P<0.01$ ).

\subsection{Disruption of NETs improves the clinical status of mice with pristane-induced} DAH

Respiratory lung function was assessed in Rh-DNase-1-treated pristane-induced DAH mice. Mice subjected to pristane-induced DAH had a significant decrease in mean arterial oxygen 
saturation compared to $\mathrm{HC}$ mice (pristane: $76.9 \%$ ( \pm 6.9 ) vs. HC: $97.9 \%( \pm 0.8), P<0.001)$. Rh-DNase-1 treated mice showed a significantly less important reduction in arterial oxygen saturation compared to untreated animals (Rh-DNase-1: $85.1 \%( \pm 6.9)$ vs. untreated: $76.9 \%$ $( \pm 6.9) ; P<0.01$, Fig. 5E). Although no difference in maximum weight loss was observed between the two groups, weight loss in Rh-DNase-1-treated mice was delayed compared to untreated animals (Fig. 5F, $P<0.001$ ). In addition, pristane-induced-DAH mice treated with Rh-DNase-1 inhalations had significantly decreased mortality at D30 compared with untreated animals (Rh-DNase-1: 35\% vs. untreated: 63\%, $P<0.05$, Fig. 5G). In agreement, PMN depletion using Ly6G Ab also reduced DAH lesions and improved arterial oxygen saturation in pristane-induced DAH compared to undepleted mice (Supplemental Fig. 3, $P<0.05)$. Taken together, these results suggest that Rh-DNase-1 inhalation therapy clears NETs, attenuates pristane-induced DAH and improves clinical status in mice.

\section{Discussion}

NETs were initially described for their antibacterial properties, in which the release of chromatin associated with neutrophil granular proteins serves as an additional weapon for the innate immune system against circulating bacteria [27]. However, increasing evidence suggests that NETs may have a detrimental role in non-infectious diseases [26]. More recently, NETs were shown to play a pathogenic role in transfusion-related acute lung injury, which is similar to autoimmune DAH in several ways [10]. Transfusion-related acute lung injury is caused by antineutrophil antibodies present in transfusion products, which induce PMN sequestration and activation in the lung capillaries, resulting in tissue injury. In a similar way, capillaritis is a hallmark of DAH and is present in $88 \%$ of patients, usually associated with fibrin thrombi and small blood vessel fibrinoid necrosis. The pathogenic mechanisms 
underlying DAH lesions are unclear. The present study suggests a pathogenic role of NETs in a murine model of DAH $[28,29]$.

Our pristane-induced DAH model is a limited organ disease and constitutes the first phase of pristane-induced SLE [11]. A recent study described morphological similarities between pristane-induced and SLE-associated DAH. However, no immune complex deposits were reported on endothelial cells or the alveolar basement membrane in the pristane model, suggesting another pathogenic mechanism. Thus a direct toxic effect of pristane could be proposed $[11,13]$. Pristane is known to have adjuvant properties and is also considered to be an irritant with subsequent cell cytotoxicity leading to necrosis, suggesting a direct chemical process different from a solely autoimmune model [14]. In addition, pristane-generated autoantibodies appeared 90 days after IP pristane injection making the indirect effect of pristane-induced autoantibody formation unlikely in this model [13, 30]. This does not exclude a role for pre-existing natural IgM reacting with apoptotic cells in the pathogenesis of this model $[13,30]$.

The role of PMNs in pristane-induced inflammation has been discussed previously. Previous studies showed that IP pristane injection induced chronic peritonitis due to PMN recruitment in the peritoneal cavity, which appeared partially dependent on IL-1 $\alpha /$ IL-1R and CXCL5/CXCR2 signalling. Consistent with previous studies, we observed PMN recruitment in the lungs of mice with pristane-induced DAH [11]. Recently, a role for macrophages in the initiation of pristane-induced DAH has been reported with the presence of activated macrophage lung infiltration and a lower prevalence of DAH after macrophage (compared to PMN) depletion [13]. Another study described the effective role of oxysterol-regulated transcription factor therapy in the prevention of pristane-induced DAH by repolarizing macrophages [31]. Without highlighting a role for macrophages, we observed less severe 
DAH lesions and improved clinical status after PMN depletion suggesting that PMNs may also participate in exacerbating DAH lesions.

Besides the well-known effect of pristane at inducing cell apoptosis in vitro and in vivo, our results show for the first time that pristane also promotes NETs generation in vitro [14]. In accordance with $56 \%$ of previous studies, our in vitro NETs experiments were performed in the absence of exogenous serum sources since a recent study demonstrated that serum components such as BSA and foetal calf serum inhibit NETs formation. Thus the choice of media supplements greatly determines the propensity to form NETs [32]. We then observed NETs in the lungs of pristane-induced DAH. NETs have been previously reported in the lungs of infectious and noninfectious-related acute lung injury in mice by confocal or electron microscopy, but they remain difficult to characterise in vivo due to their structural fragility and tissue biopsy preparation methods [7, 10, 33]. In our model, we demonstrated the presence of NETs by showing widespread DNA backbone structures with co-localization of $\mathrm{NE}$ and CitH3, in close association with PMN membranes, as revealed by IF staining. Indeed, during NETosis, NE is rapidly translocated from azurophil granules into the nucleus where it proteolitically processes histones to disrupt chromatin packaging and is then released into the extracellular space, some portions remaining bound to the PMN plasma membrane [26]. Histone citrullination catalysed by peptidylarginine deiminase-4, an enzyme prominently found in granulocytes, has also been shown to be a crucial step for PMN chromatin decondensation leading to NETs formation [34]. Because reactive oxygen species generation actively participates in NETosis, we considered that pristane triggered PMN activation ultimately leads to NETs generation [35]. Interestingly, a recent mass spectrometry study reported four characteristic peaks of pristane in the lungs and bone marrow of mice during pristane-induced DAH, suggesting wide dispersion of pristane after IP injection [13]. 
Together, these results indicate that the pristane-induced DAH model can be considered as a pulmonary model of NETosis.

Furthermore, by disrupting the NETs scaffold using Rh-DNase-1 we demonstrated a pathogenic role of NETs in this DAH model. Targeting NETs was effective at clearing the pulmonary NETs component, with a subsequent reduction in histopathological lung injury. Moreover, the clinical status of the mice improved, with a remarkable increase in arterial oxygen saturation and reduced mortality. Rh-DNase-1 is a well-known mucolytic therapy widely used in cystic fibrosis. Rh-DNase acts via disruption of extracellular DNA which interferes with mucociliary clearance, thereby reducing the rate of infectious respiratory exacerbations [36]. Interestingly, as mentioned by the Food and Drug Administration, side effects are rare, moderate and transient. A recent Cochrane database review reported an increased risk of rash $(\mathrm{RR}=2.40$ [95\%CI: 1.16-4.99]), voice alteration $(\mathrm{RR}=1.34$ [95\%CI: 0.64-2.78) and, to a lesser extent, cough and conjunctivitis. To date, no severe adverse events have been described [16]. Recently, a pilot study was conducted using adjuvant inhalation of Rh-DNase-1 for the treatment of acquired ventilator-associated infection in preterm infants. This treatment was safe and effective and led to arterial oxygenation improvement [37]. Following animal studies of transfusion-related acute lung injury, infectious acute lung injury or primary graft dysfunction after lung transplantation, our study is the first to demonstrate the beneficial effect of intrapulmonary Rh-DNase-1-induced NETs disruption during pristaneinduced DAH $[10,38,39]$. The strength of our study is the fact that in contrast to previous studies, which used intravenous or intranasal injections, we treated mice using aerosol inhalation of Rh-DNase-1 in order to mimic human clinical practice. Thus, our data clearly suggest that therapy disrupting the DNA scaffold in pristane-induced DAH is effective and could be interesting as adjuvant therapy in human autoimmune DAH. 


\section{Conclusion}

Our data suggest a pathogenic role PMNs and NETs in lung injury during pristane-induced DAH. Targeting NETs with Rh-DNase-1 inhalations could be an interesting adjuvant therapy in human DAH.

\section{Acknowledgements}

This study was supported by the "Société Nationale Française de Médecine Interne" (SNFMI), "CSL Behring”, "Groupe Pasteur Mutualité" (GPM) and "Bureau des PUPH de Marseille".

\section{Funding}

This research did not receive any specific grant from funding agencies in the public, commercial, or not-for-profit sectors. 


\section{References}

[1] A.R. Lara, M.I. Schwarz, Diffuse alveolar hemorrhage, Chest. 137 (2010) 1164-1171. https://doi.org/10.1378/chest.08-2084

[2] H. Gallagher, J.T. Kwan, D.R. Jayne, Pulmonary renal syndrome: a 4-year, singlecenter experience, Am. J. Kidney. Dis. 39 (2002) 42-47. https://doi.org/10.1053/ajkd.2002.29876

[3] M.R. Zamora, M.L. Warner, R. Tuder, M.I. Schwarz, Diffuse alveolar hemorrhage and systemic lupus erythematosus. Clinical presentation, histology, survival, and outcome, Medicine (Baltimore). 76 (1997) 192-202.

[4] N. de Prost, A. Parrot, E. Cuquemelle, C. Picard, M. Antoine, J. Fleury-Feith, et al, Diffuse alveolar hemorrhage in immunocompetent patients: etiologies and prognosis revisited, $\quad$ Resp. $\quad$ Med. $\quad 106 \quad$ (2012) 1021-1032. https://doi.org/10.1016/j.rmed.2012.03.015

[5] T.V. Colby, J. Fukuoka, S.P. Ewaskow, R. Helmers, K.O. Leslie, Pathologic approach to pulmonary hemorrhage, Ann. Diagn. Pathol. 5 (2001) 309-319. Https://do.org/10.1053/adpa.2001.27923 
[6] V. Brinkmann, Neutrophil extracellular traps in the second decade, J. Innate Immun. 10 (2018) 414-421. https://doi.org/10.1159/000489829

[7] B.N. Porto, R.T. Stein, Neutrophil extracellular traps in pulmonary diseases: too much of a good thing? Front Immunol. $7 \quad$ (2016) 311. https://doi.org/10.3389/fimmu.2016.00311

[8] F. Apel, A. Zychlinsky, E.F. Kenny, The role of neutrophil extracellular traps in rheumatic diseases, Nat. Rev. Rheumatol. 14 (2018) 467-475. https://doi.org/10.1038/s41584-018-0039-z

[9] A. Caudrillier, K. Kessenbrock, B.M. Gilliss, J.X. Nguyen, M.B. Marques, M. Monestier, et al, Platelets induce neutrophil extracellular traps in transfusion-related acute lung injury, J Clin Invest, $122 \quad$ (2012) 2661-2671. https://doi.org/10.1172/JCI61303

[10] G.M. Thomas, C. Carbo, B.R. Curtis, K. Martinod, I.B. Mazo, D. Schatzberg, et al, Extracellular DNA traps are associated with the pathogenesis of TRALI in humans and mice, Blood. 119 (2012) 6335-6343. https://doi.org/10.1182/blood-2012-01405183

[11] V.R. Chowdhary, J.P. Grande, H.S. Luthra, C.S. David, Characterization of haemorrhagic pulmonary capillaritis: another manifestation of pristane-induced lupus, $\begin{array}{llll}\text { Rheumatology } & \text { (Oxford). } & 46 \quad \text { 1405-1410. }\end{array}$ https://doi.org/10.1093/rheumatology/kem117

[12] M. Satoh, J.P. Weintraub, H. Yoshida, V.M. Shaheen, H.B. Richards, M. Shaw, et al, Fas and Fas ligand mutations inhibit autoantibody production in pristane-induced lupus, J. Immunol. 165 (2000) 1036-1043. 
[13] H. Zhuang, S. Han, P.Y. Lee, R. Khaybullin, S. Shumyak, L. Lu, et al, Pathogenesis of diffuse alveolar hemorrhage in murine lupus, Arthritis Rheumatol. 69 (2017) 12801293. https://doi.org/10.1002/art.40077

[14] S. Herman, A. Kny, C. Schorn, J. Pfatschbacher, B. Niederreiter, M. Herrmann, et al, Cell death and cytokine production induced by autoimmunogenic hydrocarbon oils, Autoimmunity. 45 (2012) 602-611. https://doi.org/10.3109/08916934.2012.719948

[15] P.Y. Lee, Y. Kumagai, Y. Xu, Y. Li, T. Barker, C. Liu, et al, IL-1alpha modulates neutrophil recruitment in chronic inflammation induced by hydrocarbon oil, $\mathrm{J}$. Immunol. 186 (2011) 1747-1754. https://doi.org/10.4049/jimmunol.1001328

[16] C. Yang, M. Montgomery, Dornase alfa for cystic fibrosis, Cochrane Database Syst. Rev. 9 (2018) Cd001127. https://doi.org/10.1002/14651858.CD001127.pub4

[17] M. Swamydas, Y. Luo, M.E. Dorf, M.S. Lionakis, Isolation of mouse neutrophils, $\begin{array}{llll}\text { Curr. } & \text { Protoc. } & \text { Immunol. } & \end{array}$ https://doi.org/10.1002/0471142735.im0320s110

[18] K. Farley, J.M. Stolley, P. Zhao, J. Cooley, E. Remold-O'Donnell, A serpinB1 regulatory mechanism is essential for restricting neutrophil extracellular trap $\begin{array}{lllll}\text { generation, } & \text { J. } & \text { Immunol. } & 189 & \text { (2012) }\end{array}$ https://doi.org/10.4049/jimmunol.1201167

[19] S. Janz, E. Shacter, A new method for delivering alkanes to mammalian cells: preparation and preliminary characterization of an inclusion complex between betacyclodextrin and pristane (2,6,10,14-tetramethylpentadecane), Toxicology. 69 (1991) $301-315$

[20] C. Carmona-Rivera, M.J. Kaplan, Induction and quantification of NETosis, Curr. Protoc. Immunol. 115 (2016) 14.41.1-14.41.14. https://doi.org/10.1002/cpim.16 
[21] A. Mangold, A. Mitterbauer, B. Moser, H.J. Ankersmit, K. Hoetzenecker, M. Zimmermann, et al, Phosphate buffered saline containing calcium and magnesium elicits increased secretion of interleukin-1 receptor antagonist, Lab. Med. 40 (2009) 290-293.

[22] J.M. Daley, A.A. Thomay, M.D. Connolly, J.S. Reichner, J.E. Albina, Use of Ly6Gspecific monoclonal antibody to deplete neutrophils in mice, J. Leukoc. Biol. 83 (2008) 64-70. https://doi.org/10.1189/jlb.0407247

[23] K.W. Bruhn, K. Dekitani, T.B. Nielsen, P. Pantapalangkoor, B. Spellberg, Ly6Gmediated depletion of neutrophils is dependent on macrophages, Results Immun. 6 (2016) 5-7. https://doi.org/10.1016/j.rinim.2015.12.001

[24] E. Abraham,A. Carmody, R. Shenkar, J. Arcaroli, Neutrophils as early immunologic effectors in hemorrhage- or endotoxemia-induced acute lung injury, Am. J. Physiol. Lung Cell. Mol, Physiol. 279 (2000) L1137-1145. https://doi.org/10.1152/ajplung.2000.279.6.L1137

[25] T.T. Barker, P.Y. Lee, K.M. Kelly-Scumpia, J.S. Weinstein, D.C. Nacionales, Y. Kumagai, et al, Pathogenic role of B cells in the development of diffuse alveolar hemorrhage induced by pristane, Lab. Invest. 91 (2011) 1540-1550. https://doi.org/10.1038/labinvest.2011.108

[26] V. Papayannopoulos, Neutrophil extracellular traps in immunity and disease, Nat. Rev. Immunol. 18 (2018) 134-147. https://doi.org/10.1038/nri.2017.105

[27] V. Brinkmann, U. Reichard, C. Goosmann, B. Fauler, Y. Uhlemann, D.S. Weiss, et al, Neutrophil extracellular traps kill bacteria, Science. 303 (2004) 1532-1535. https://doi.org/10.1126/science.1092385

[28] M.S. Park, Diffuse alveolar hemorrhage, Tuberc. Respir. Dis (Seoul). 74 (2013) 151162. https://doi.org/10.4046/trd.2013.74.4.151 
[29] T.J. Franks, M.N. Koss, Pulmonary capillaritis, Curr. Opin. Pulm. Med. 6 (2000) 430435.

[30] E.C. Freitas, M.S. de Oliveira, O.A. Monticielo, Pristane-induced lupus: considerations on this experimental model, Clin. Rheumatol. 36 (2017) 2403-2414. https://doi.org/10.1007/s10067-017-3811-6

[31] S. Han, H. Zhuang, S. Shumyak, J. Wu, C. Xie, H. Li, et al, Liver X receptor agonist therapy prevents diffuse alveolar hemorrhage in murine lupus by repolarizing $\begin{array}{llllll}\text { macrophages, } & \text { Front } & \text { Immunol. } & 9 & \text { (2018) }\end{array}$ https://doi.org/10.3389/fimmu.2018.00135

[32] E. Neubert, S.N. Senger-Sander, V.S. Manzke, J. Busse, E. Polo, S.E.F. Scheidmann, et al, Serum and serum albumin inhibit in vitro formation of neutrophil extracellular $\begin{array}{llllll}\text { traps } & \text { (NETs), } & \text { Front } & \text { Immunol. } & 10 & \text { (2019) }\end{array}$ https://doi.org/10.3389/fimmu.2019.00012

[33] T. Onouchi, K. Shiogama, T. Matsui, Y. Mizutani, K. Sakurai, K. Inada, et al, Visualization of neutrophil extracellular traps and fibrin meshwork in human fibrinopurulent inflammatory lesions: II. Ultrastructural study, Acta Histochem. Cytochem. 49 (2016) 117-123. https://doi.org/10.1267/ahc.16016

[34] T.A.M. Claushuis, L.E.H. van der Donk, A.L. Luitse, H.A. van Veen, N.N. van der Wel, L.A. van Vught, et al, Role of peptidylarginine deiminase 4 in neutrophil extracellular trap formation and host defense during Klebsiella pneumoniae-induced pneumonia-derived sepsis, J. Immunol. $201 \quad$ (2018) 1241-1252. https://doi.org/10.4049/jimmunol.1800314

[35] D. Kienhofer, J. Hahn, J. Stoof, J.Z. Csepregi, C. Reinwald, V. Urbonaviciute, et al, Experimental lupus is aggravated in mouse strains with impaired induction of 
$\begin{array}{llllll}\text { neutrophil extracellular traps, JCI } & \text { Insight. } & 2 & \text { (2017). }\end{array}$ https://doi.org/10.1172/jci.insight.92920

[36] C.L. Yang, M. Chilvers, M. Montgomery, S.J. Nolan, Dornase alfa for cystic fibrosis, Paediatr. Resp. Rev. 21 (2017) 65-67. https://doi.org/10.1016/j.prrv.2016.09.001

[37] M. Scala, D. Hoy, M. Bautista, J.J. Palafoutas, K. Abubakar, Pilot study of dornase alfa (Pulmozyme) therapy for acquired ventilator-associated infection in preterm infants, Pediatr. Pulmonol. 52 (2017) 787-791. https://doi.org/10.1002/ppul.23656

[38] M.K. Sercundes, L.S. Ortolan, D. Debone, P.V. Soeiro-Pereira, E. Gomes, E.H. Aitken, et al, Targeting neutrophils to prevent malaria-associated acute lung injury/acute respiratory distress syndrome in mice, PLoS Pathog. 12 (2016) e1006054. https://doi.org/10.1371/journal.ppat.1006054

[39] D.M. Sayah, B. Mallavia, F. Liu, G. Ortiz-Munoz, A. Caudrillier, A. DerHovanessian, et al, Neutrophil extracellular traps are pathogenic in primary graft dysfunction after lung transplantation, Am. J. Respir. Crit. Care. Med. 191 (2015) 455-463. https://doi.org/10.1164/rccm.201406-1086OC 


\section{Figure legends}

Figure 1. Pristane-induced neutrophil extracellular traps (NETs) generation in vitro.

(A, B, C) Representative immunofluorescence (IF) images of NETs from PMNs either unstimulated (HKS) or stimulated with $10 \mu \mathrm{M}$ platelet activating factor (PAF) or pristane (C1): (A) direct IF staining of DNA (blue) and control irrelevant antibodies (green); (B) direct IF staining of DNA (blue) and neutrophil elastase (NE) (green); (C) direct IF staining of DNA (blue) and H3Cit (red). Magnification x100, scale bar $100 \mu \mathrm{m}$. (D) Quantification of NETs released from PMNs stimulated with PAF, with different concentrations of $\beta$-CD-pristane $(\mathrm{C} 1$, $\mathrm{C} 1 / 10, \mathrm{C} 2$ ) and with direct application of pristane (DA): quantification of NETs by evaluating PMNs releasing DNA fibres with NE co-staining (circle), quantification of NETs by evaluating PMNs releasing DNA fibres with H3Cit co-staining (square). Results represent mean \pm SD. $* * * P<0.001$ (by t-test) compared with unstimulated or $\beta-C D-s t i m u l a t e d ~ P M N s$.

Figure 2. Neutrophil extracellular traps (NETs) formation in the lungs of mice with pristane-induced diffuse alveolar hemorrhage (DAH).

(A, B) Lung tissue from healthy control (HC) mice and mice with pristane-induced DAH: (A) cryosections were stained for DNA (blue), Ly6G (red) and neutrophil elastase (NE) (green); (B) cryosections were stained for DNA (blue), Ly6G (red) and H3Cit (green). Magnification x100, scale bar $100 \mu \mathrm{m}$. (C) Quantification of the release of NE (circle) and H3Cit (square) in the lungs from $\mathrm{HC}$ mice or mice with pristane-induced DAH (mean $\pm \mathrm{SD} ; * * * P<0.001, \mathrm{n}=6$ mice per condition) compared with HC mice. (D) Quantification of PMNs in the lungs from $\mathrm{HC}$ mice or mice with pristane-induced $\mathrm{DAH}$ (mean $\pm \mathrm{SD} ; * * * P<0.001, \mathrm{n}=6$ mice per condition) compared with HC mice. (E, F) Confocal fluorescence microscopy of lung tissue from a mouse with pristane-induced DAH: (E) cryosections stained for DNA (blue), Ly6G (red) and NE (green); (F) cryosections stained for DNA (blue), Ly6G (red) and H3Cit (green). DNA 
structures with colocalization of Ly6G (corresponding to PMN membranes) and with NE or H3Cit staining, in favour of NETs (arrows). Magnification x630, scale bar $10 \mu \mathrm{m}$.

Figure 3. Depletion of PMNs prevents neutrophil extracellular traps (NETs) generation. (A) Flow cytometry analysis of blood from healthy control (HC) mice treated 14 days previously with pristane, without depletion, or with depletion using anti-Ly6G Ab (1A8). Left, surface staining with anti-CD45-efluor780 and anti-CD11b-APC antibodies. Right, among the CD45 and CD11b positive cells, staining with anti-Ly6G-PE showing the percentage of PMNs. (B, C) Lung tissue from mice with pristane-induced diffuse alveolar haemorrhage (DAH) with or without PMN depletion: (B) cryosections immunostained for DNA (blue), Ly6G (red) and neutrophil elastase (NE) (green); (C) cryosections immunostained for DNA (blue), Ly6G (red) and H3Cit (green). Magnification x100, scale bar $100 \mu \mathrm{m}$. (D) Quantification of the release of $\mathrm{NE}$ (circle) and H3Cit (square) in lungs from mice with pristane-induced DAH with or without PMN depletion (mean $\pm \mathrm{SD} ; * * * P<0.001, \mathrm{n}=6$ mice per condition) compared with undepleted mice.

Figure 4. Recombinant human DNase-1 inhalation therapy disrupts neutrophil extracellular traps (NETs) formation in pristane-induced diffuse alveolar hemorrhage (DAH).

(A, B) Lung tissue from mice with pristane-induced DAH with or without Rh-DNase-1 inhalation therapy: (A) cryosections immunostained for DNA (blue), Ly6G (red) and neutrophil elastase (NE) (green); (B) cryosections immunostained for DNA (blue), Ly6G (red) and H3Cit (green). Magnification x100, scale bar $100 \mu \mathrm{m}$. (C) Quantification of NE release in lungs from mice injected with PBS and from mice with pristane-induced DAH with or without Rh-DNase1 inhalation therapy (mean $\pm \mathrm{SD} ; * * * P<0.001, \mathrm{n}=6$ mice per condition) compared with 
untreated mice. (D) Quantification H3Cit release in lungs from mice injected with PBS and from mice with pristane-induced DAH with or without Rh-DNase-1 inhalation therapy (mean $\pm \mathrm{SD} ; * * * P<0.001, \mathrm{n}=6$ mice per condition), compared with untreated mice. (E) Quantification of PMN in lungs from mice injected with PBS and from mice with pristane-induced DAH with or without Rh-DNase-1 inhalation therapy (mean $\pm \mathrm{SD} ; * * * P<0.001, \mathrm{n}=6$ mice per condition), compared with untreated mice.

Figure 5. Recombinant human DNase-1 inhalation therapy reduces lesions of acute lung injury and improves clinical status.

(A) Macroscopic view of the left lobes from a healthy control (HC) mouse and a mouse with pristane-induced diffuse alveolar hemorrhage (DAH) (pristane) with or without Rh-DNase-1 inhalation therapy (pristane/DNase-1). (B, C) Representative haematoxylin-eosin staining of the left lobe from a $\mathrm{HC}$ mouse and a mouse with pristane-induced DAH (pristane) with or without Rh-DNase-1 inhalation therapy (pristane/DNase-1): (B) magnification x20, scale bar $500 \mu \mathrm{m}$; (C) magnification x100, scale bar $100 \mu \mathrm{m}$. (D) Quantification of hemorrhage in the left lobe of mice challenged intraperitoneally (IP) with pristane, with or without Rh-DNase-1 therapy (mean $\pm \mathrm{SD} ; * * P<0.01, \mathrm{n}=8$ mice per condition), compared with untreated mice. (E) Mean arterial oxygen saturation in mice challenged with IP pristane or with PBS, with or without Rh-DNase-1 inhalation therapy (mean $\pm \mathrm{SD} ; * * P<0.01, \mathrm{n}=12$ mice per condition), compared with untreated mice. (F) Number of mice with pristane-induced DAH with or without Rh-DNase-1 inhalation therapy who achieved their maximum weight loss before day 15 (mean $\pm \mathrm{SD} ; * * * P<0.001, \mathrm{n}=15$ per condition) compared with untreated mice. (G) 30-day mortality rate in mice with pristane-induced DAH with or without Rh-DNase-1 inhalation therapy $(* P<0.05$, by log-rank (Mantel-Cox test, $\mathrm{n}=19$ per condition) compared with control mice $(\mathrm{NaCl} 0.9 \%)$. 
Figure 1
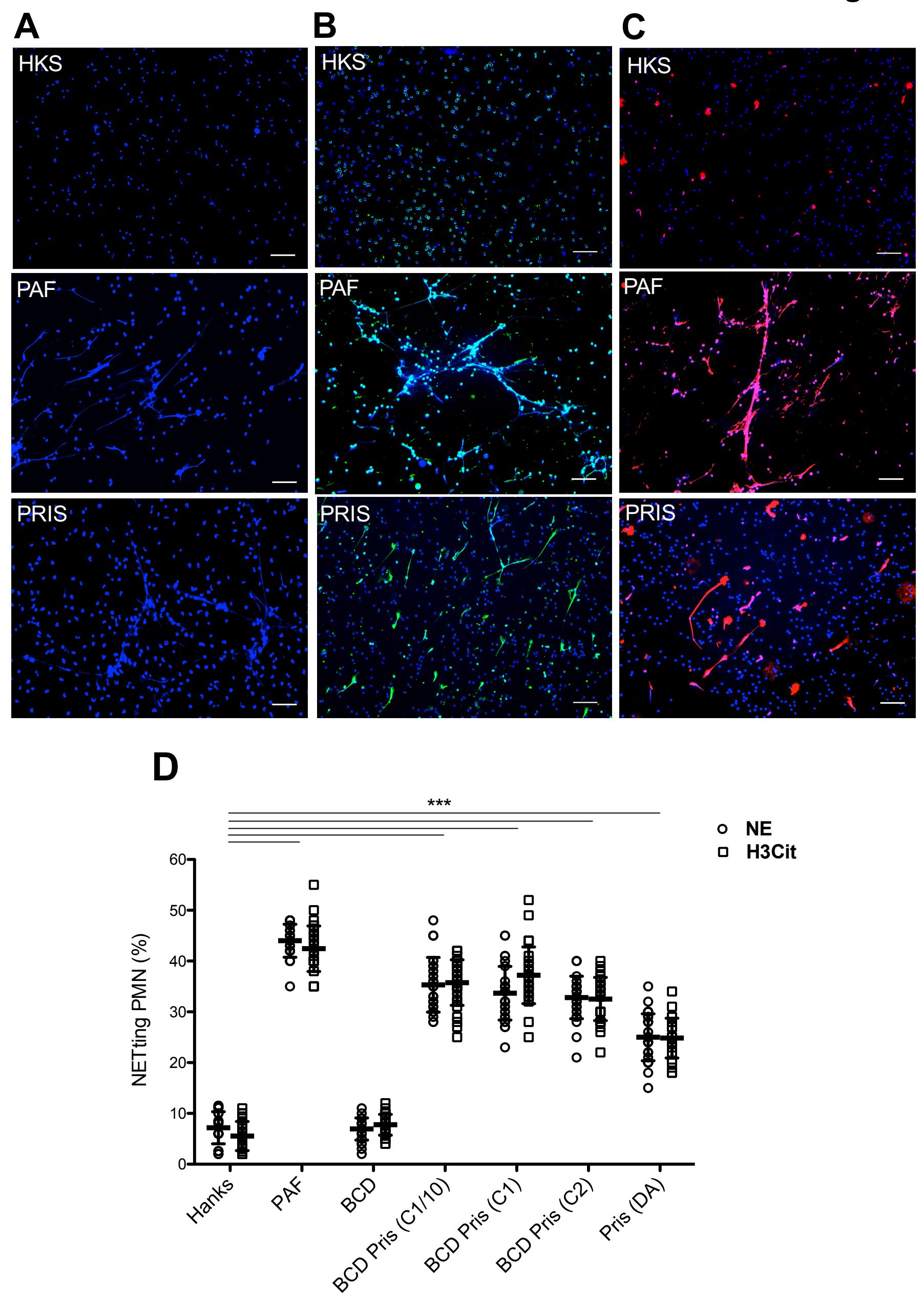

- NE

口 H3Cit 
Figure 2

A

Healthy Control

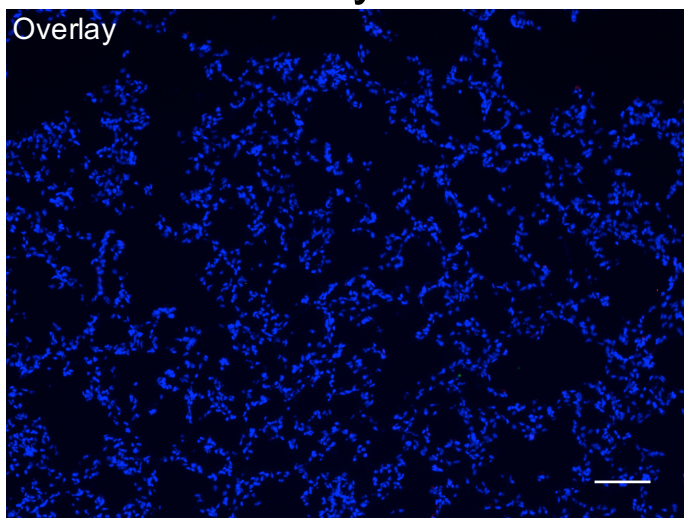

\section{Pristane}

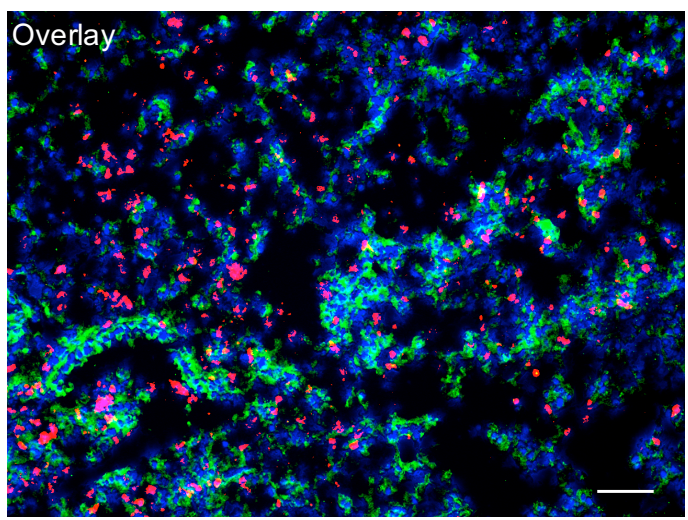

C

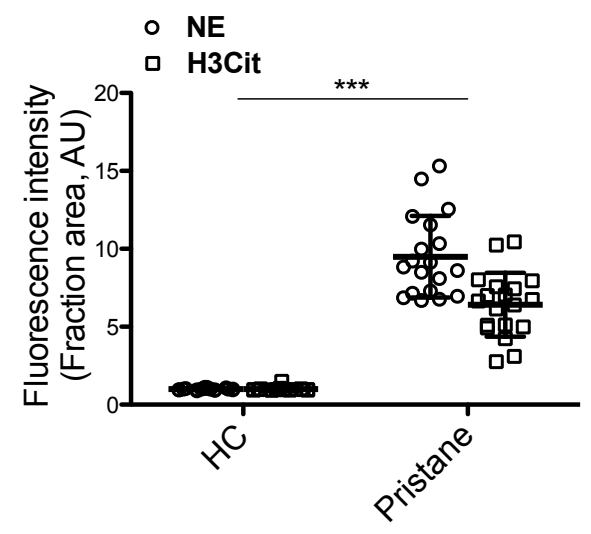

D

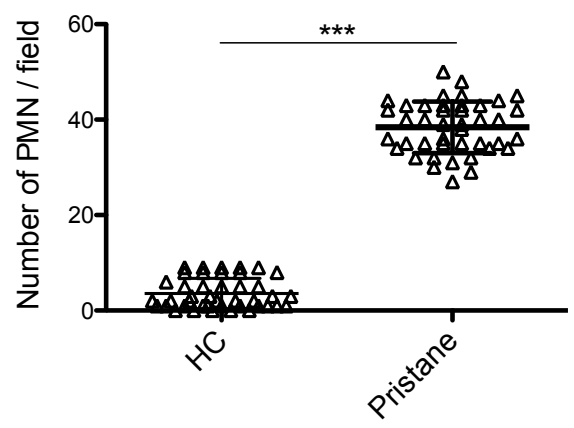

E

Overlay

F
B

Healthy Control

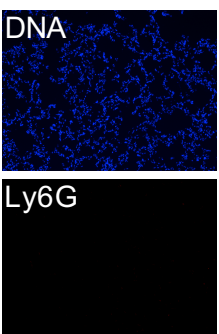

NE

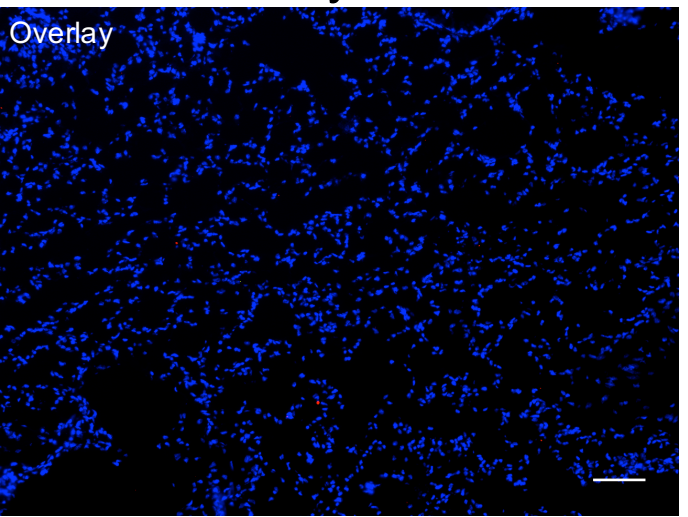

\section{Pristane}
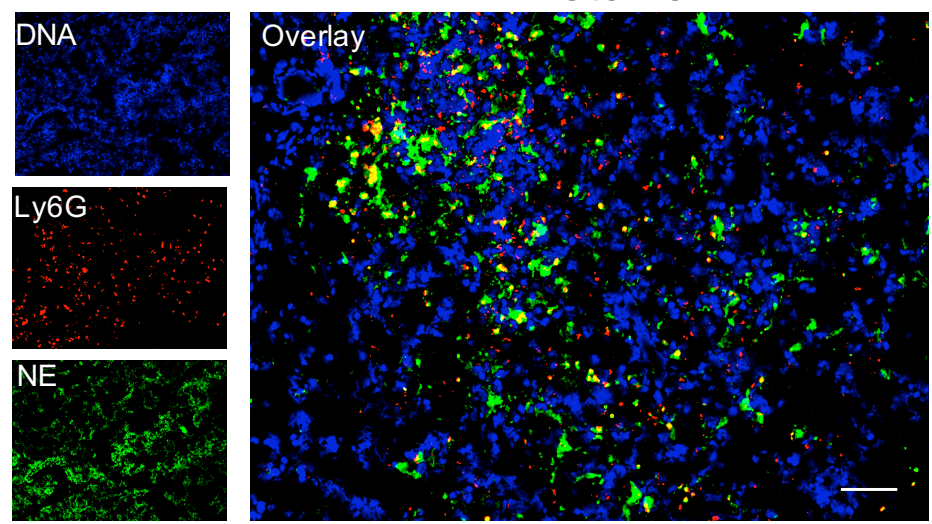

DNA

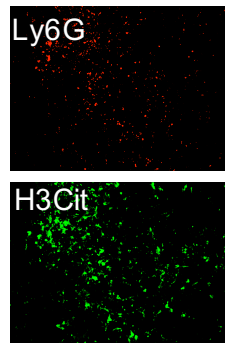

DNA

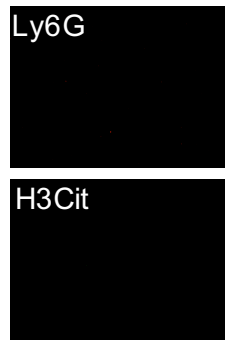

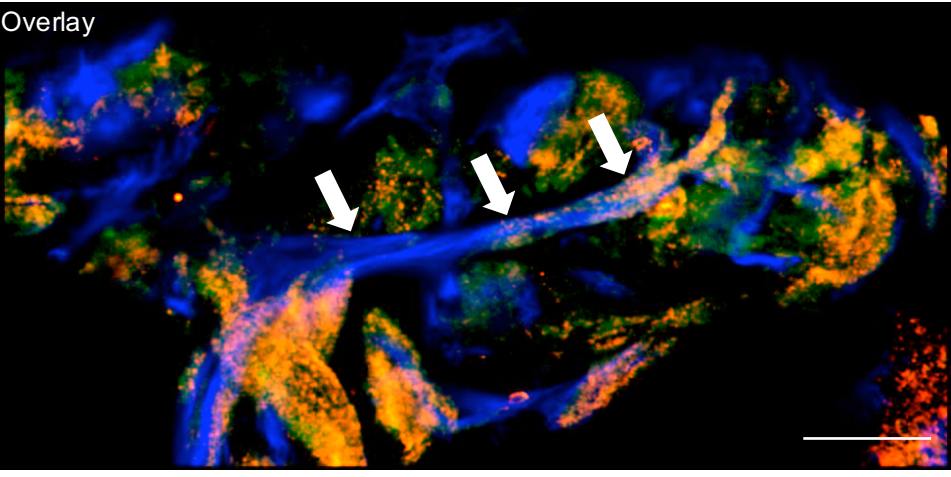
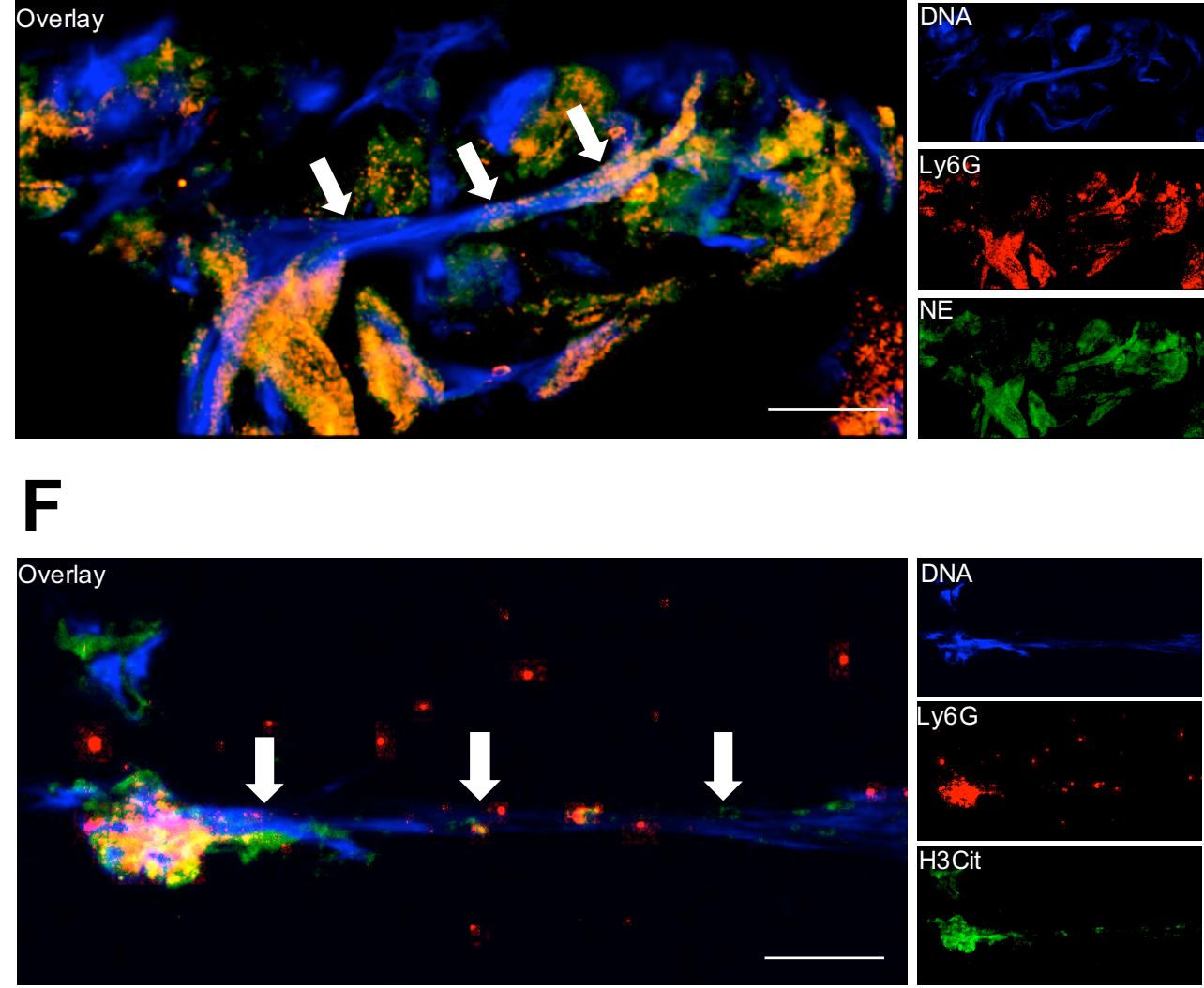
Pristane

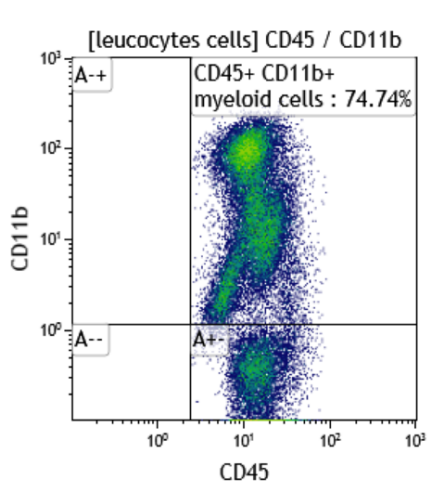

B

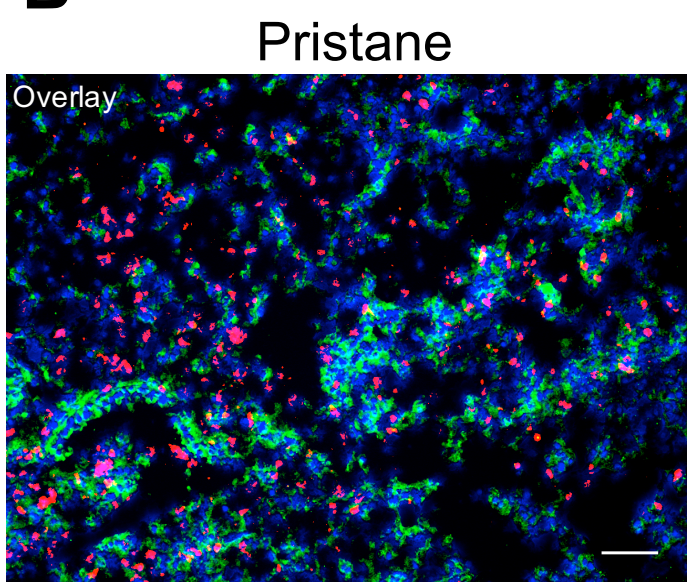

Pristane / PMN depleted
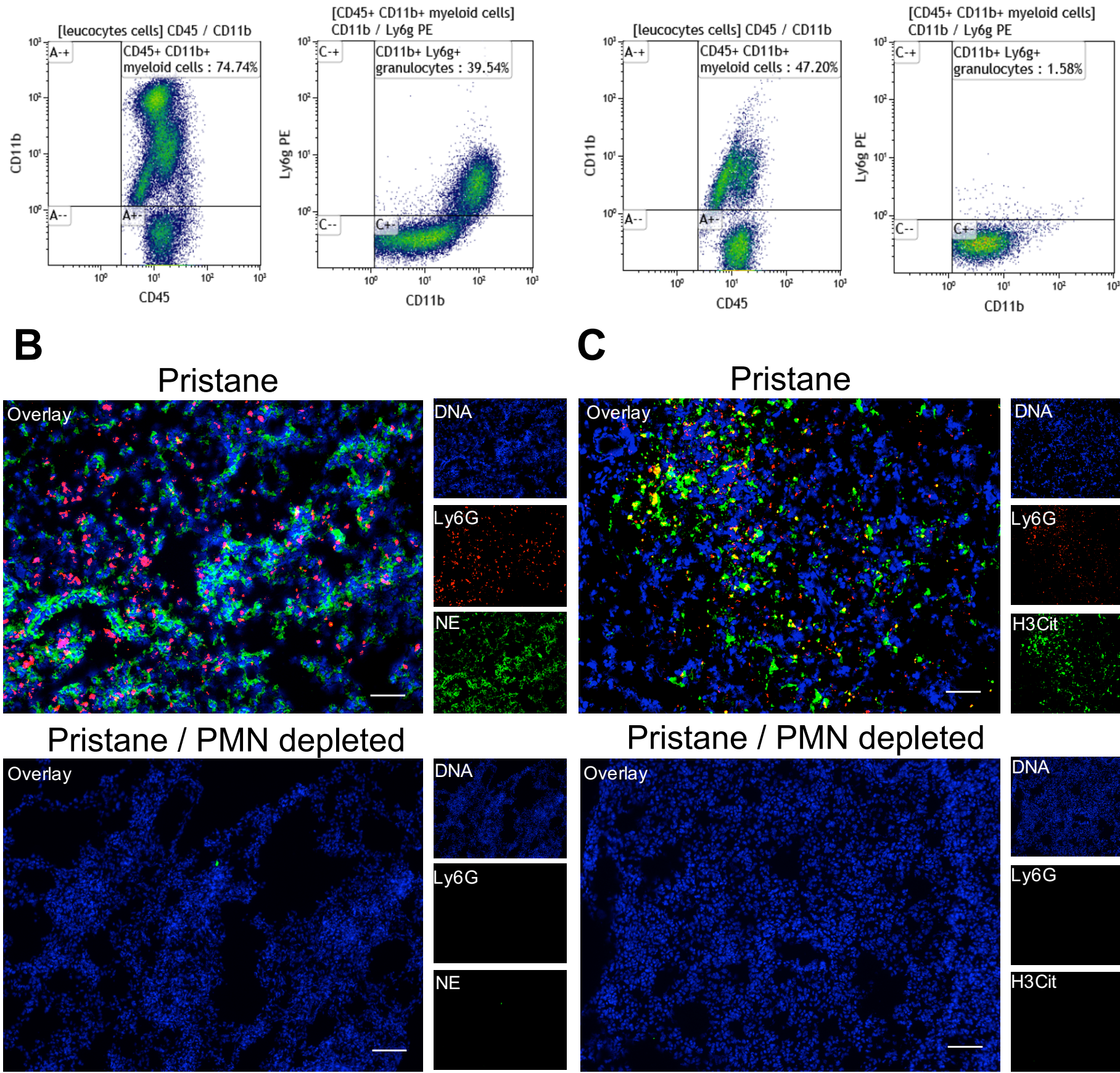

C
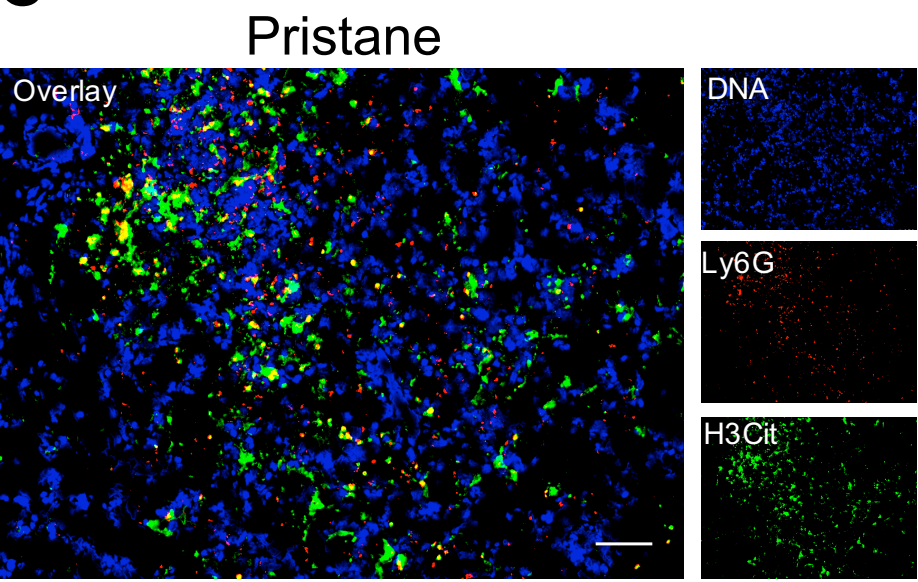

Pristane / PMN depleted
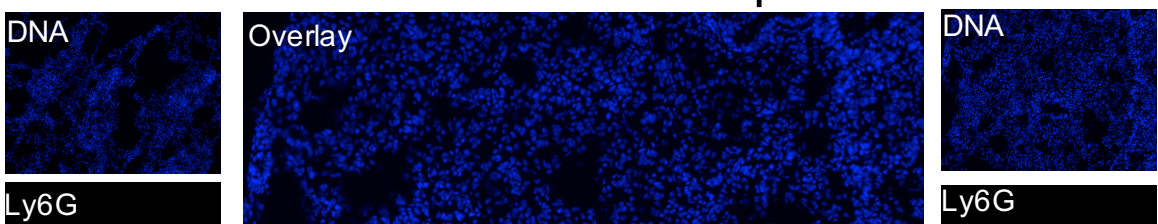

Ly6G

Ly6G

NE

$\mathrm{NE}$

erlay

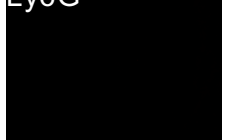

H3Cit

○ NE

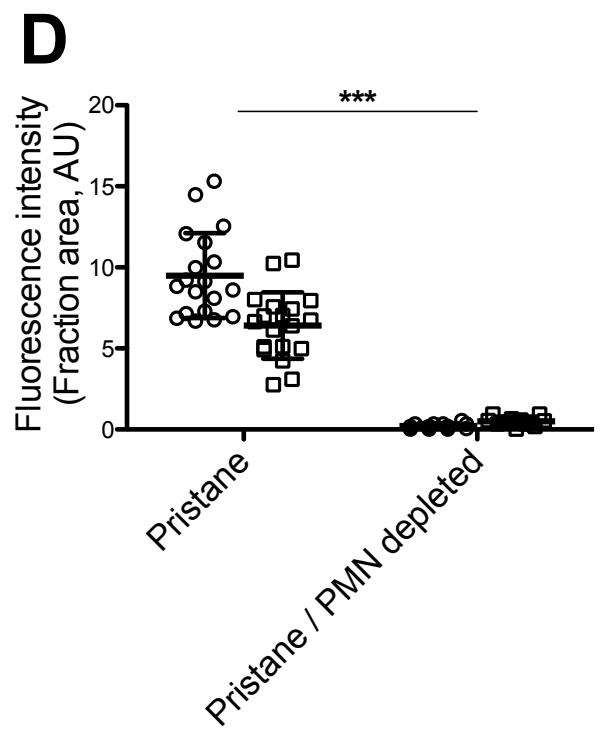

口 $\mathrm{H} 3 \mathrm{Cit}$ 
Figure 4

A

\section{Pristane}

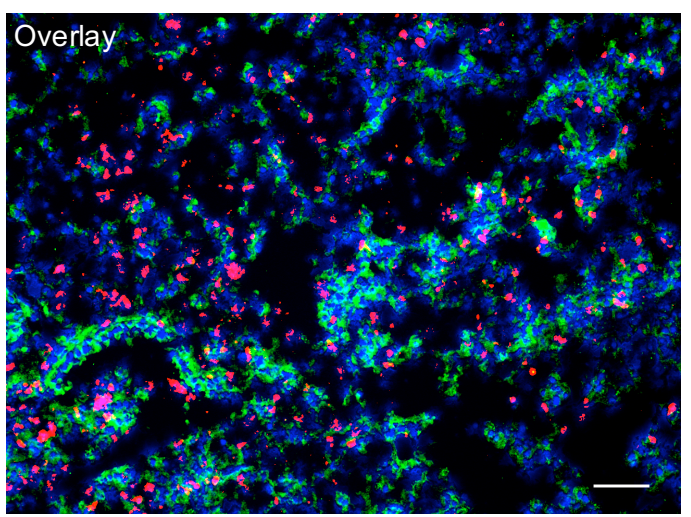

Pristane / DNase-1

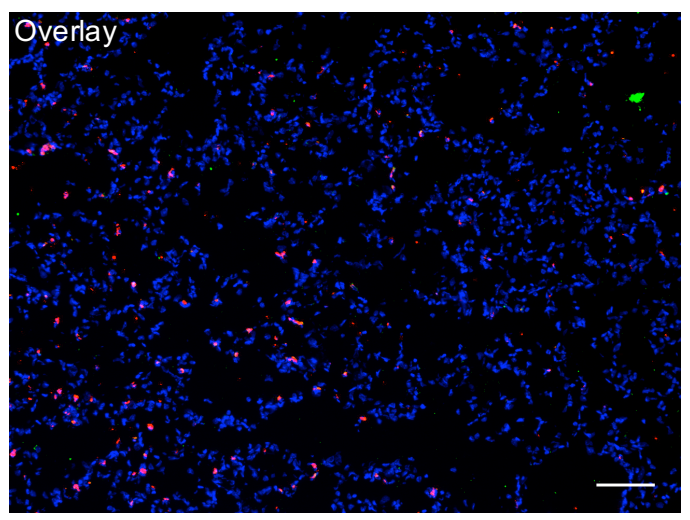

C
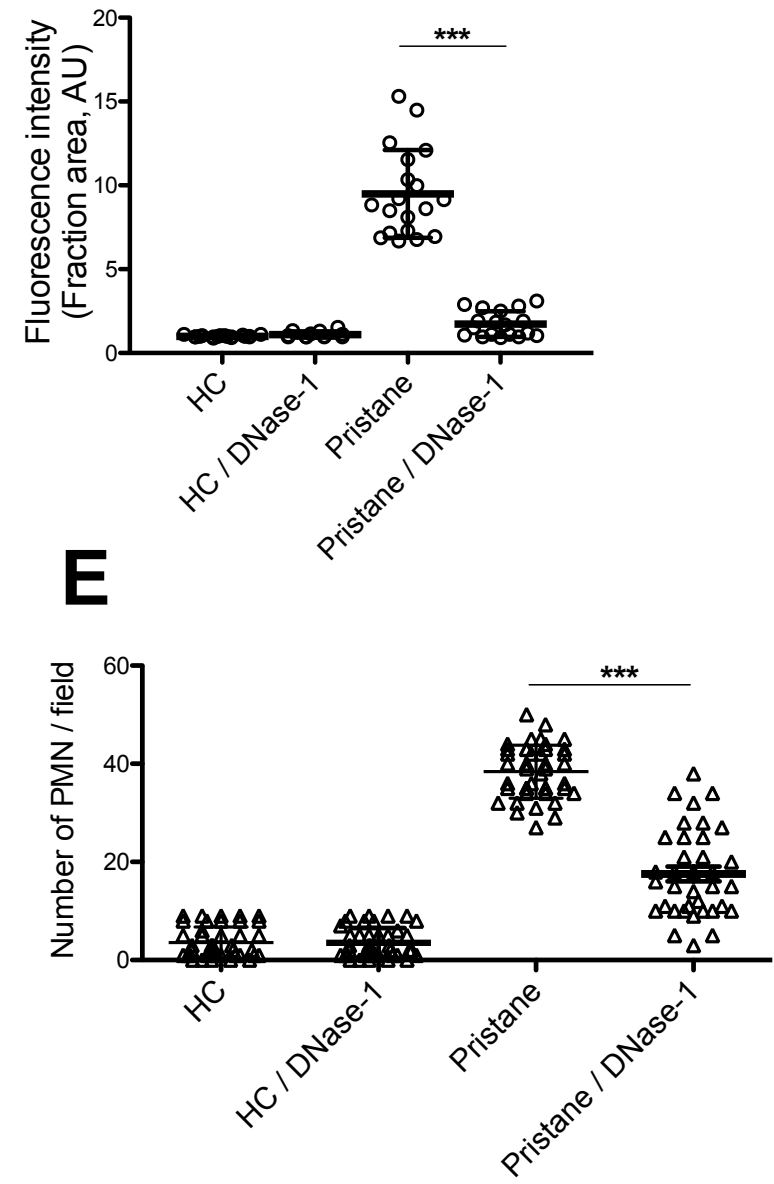

Pristane
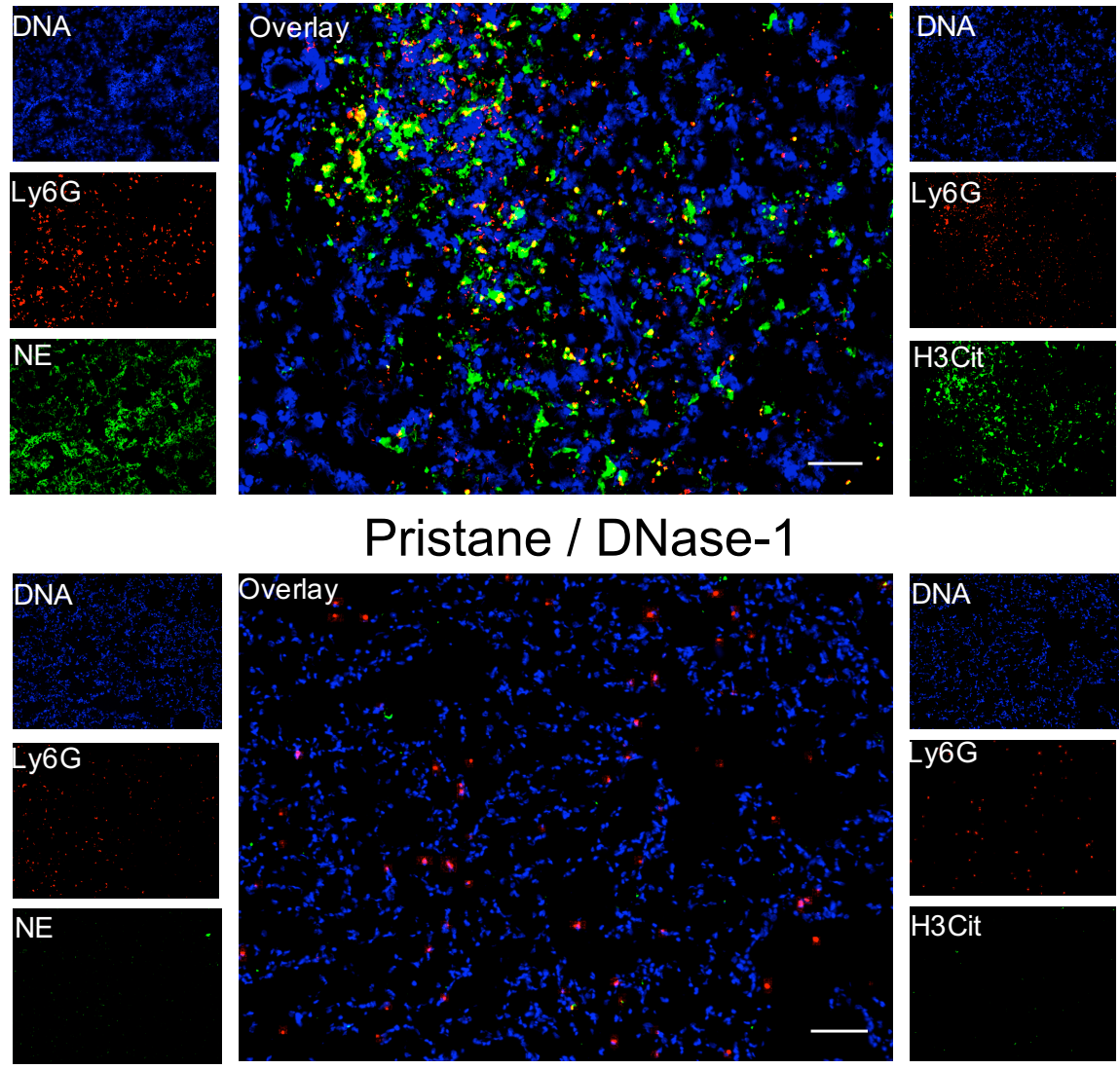

H3Cit
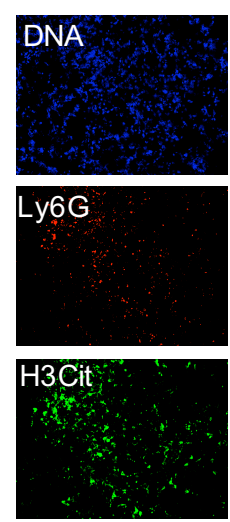

Pristane / DNase-1
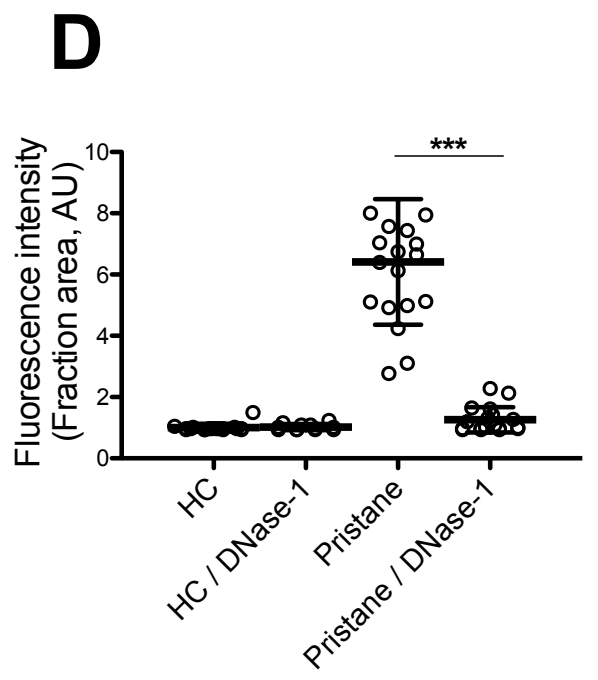


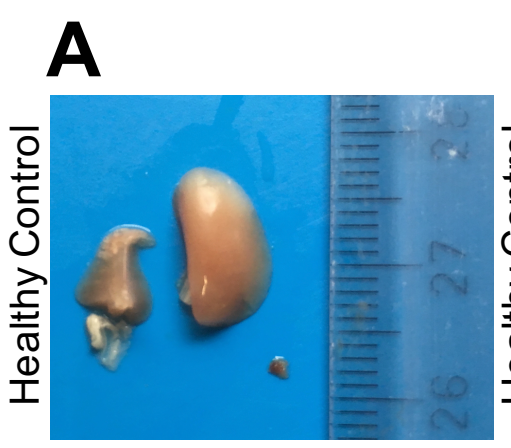

B
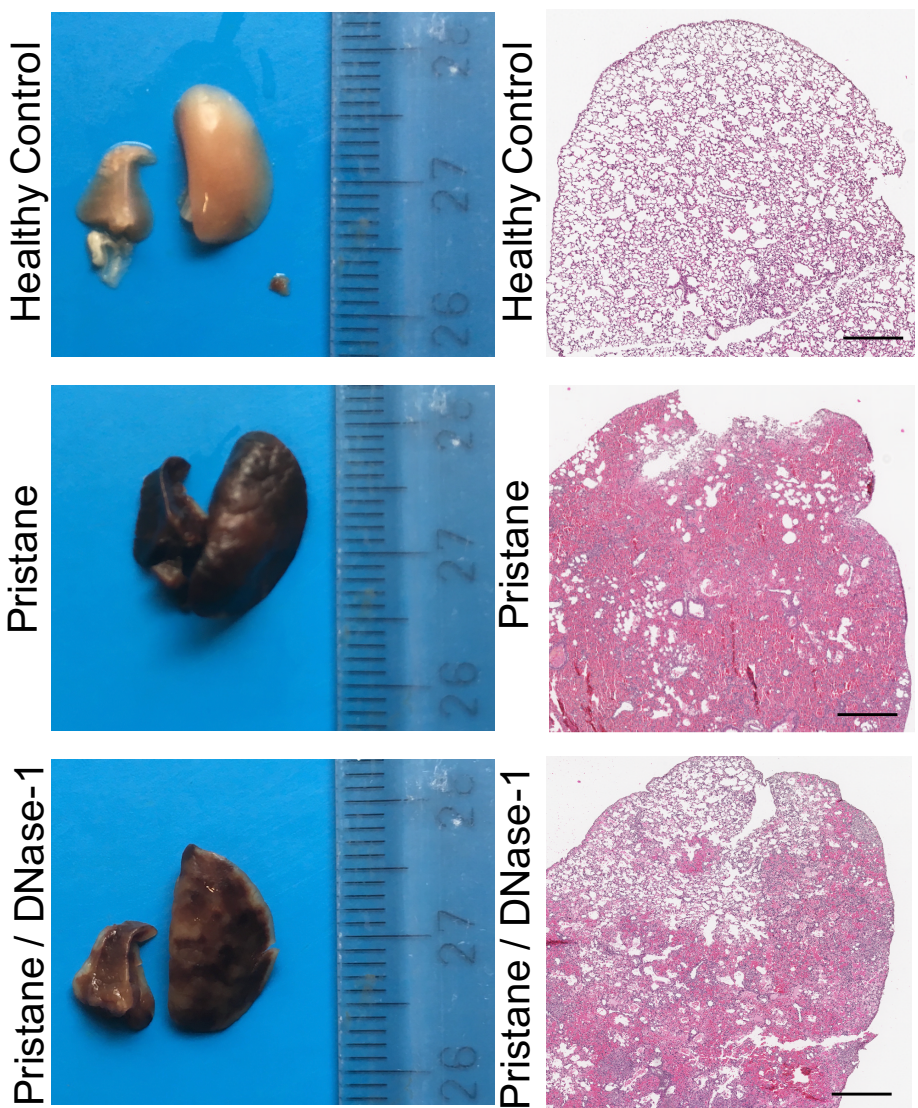

D

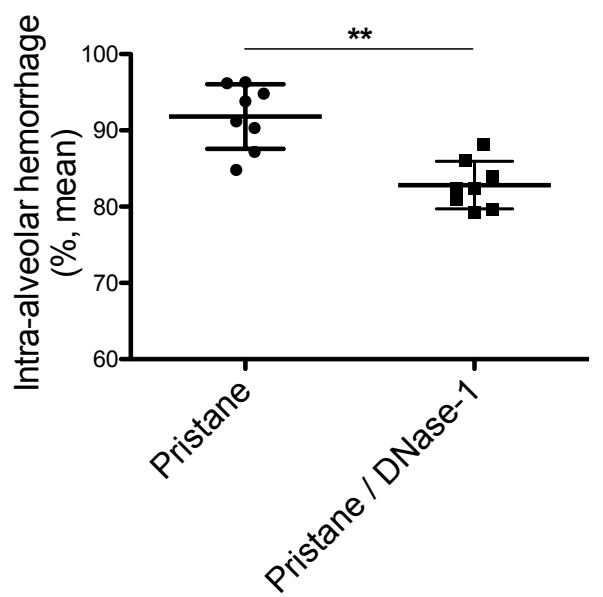

F
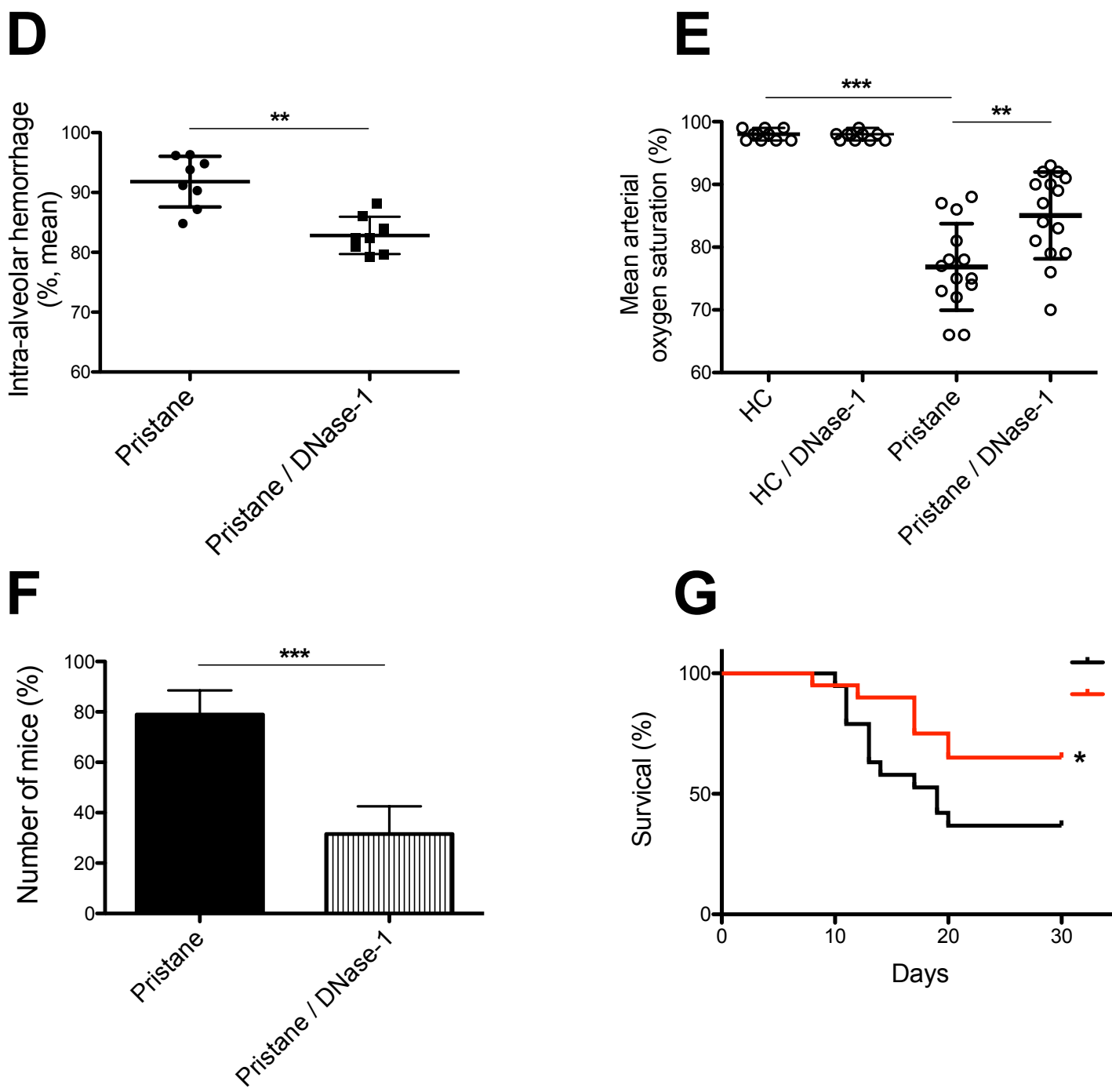

\section{G}

C

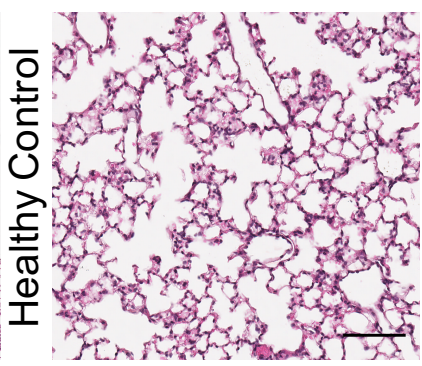

Figure 5
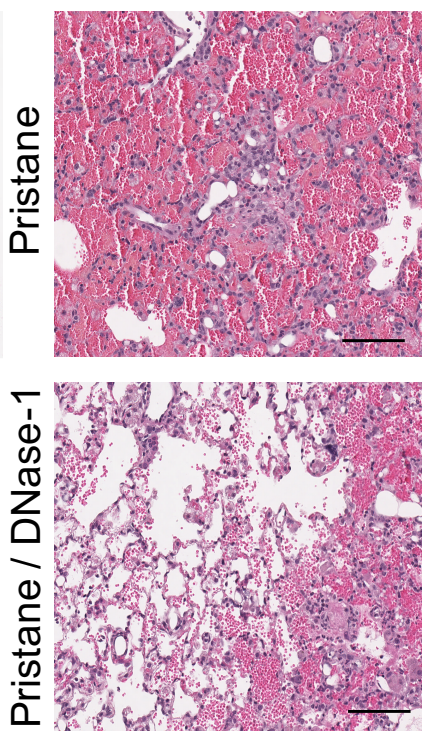

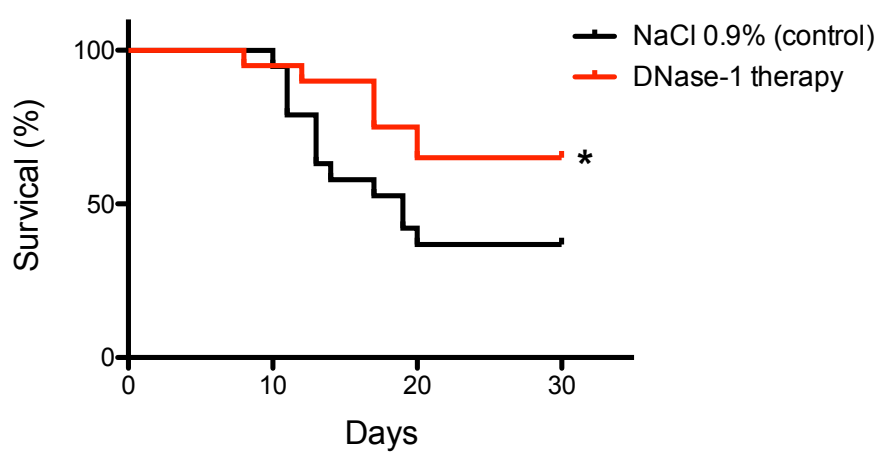

